\title{
Prevalence of Antimicrobial Drug Resistance of Klebsiella pneumoniae in India
}

\author{
Archana Singh Sikarwar and Harsh Vardhan Batra
}

\begin{abstract}
Klebsiella pneumoniae has been associated with different types of infections and one of the most important aspects of Klebsiella is the emergence of multi-drug resistant strains particularly those involved in nosocomial diseases. Fifty - nine clinical isolates were collected from different parts of India. Most of the samples were recovered from respiratory, urinary tract infection and pus cases which were followed by biochemical characterization. Twenty confirmed $K$. pneumoniae isolates were further tested for antimicrobial drug sensitivity and almost fifty percent of them were found to be multidrug resistant. As per our statistical data, all confirmed K.pneumoniae isolates were resistant to carbenicillin and one among them recovered from sputum sample of a pneumonic patient was resistant to all the antimicrobial agents tested except exhibiting a partial susceptibility to amikacin. In our studies we found that K.pneumoniae strains from clinical cases were highly susceptible to quinolones and the aminoglycoside, amykacin and gentamycin. At the same time over $60 \%$ strains were resistant to chloramphenicol and tetracycline. We also found that 28 to $76 \%$ of them were resistant to cephalosporins (ceftizoxime and cefotaxime). On the basis of statistical binomial test we conclude that piperacillin, carbenicillin, ofloxacine ampicillin, co-trimoxazole and chloramphenicol were significantly resistant, whereas cefotaxime and tetracycline were found to be moderately resistant against Klebsiella pneumoniae.
\end{abstract}

Index Terms-Antibiotic, antimicrobial drug resistance, Klebsiella pneumoniae

\section{INTRODUCTION}

In 1883 Friedlander isolated a capsulated bacillus from the lungs of patient who died of pneumonia. This was named after him as Friedlander's bacillus. Later on this organism was given the generic name of Klebsiella, which is ubiquitously present and reported worldwide. Strains of Klebsiella are responsible for a wide variety of diseases in humans. These bacteria have become important pathogens in nosocomial infections [1] which have been well documented in United States [2] and India [3]. Epidemic and endemic nosocomial infections caused by Klebsiella species are leading causes of morbidity and mortality [4]. In addition to being the primary cause of respiratory tract infections, it is

Manuscript received June 25, 2011; revised August 29, 2011. This work was funded by the, Graduate Aptitude test for Engineering fellowship, Ministry of Human Resources, India.

Archana Singh Sikarwar is with Medicine and Health Sciences Department at International Medical University, Bukit Jalil, Kuala Lumpur phone: +60 32731 7274; fax: +60 3 86567229; (e-mail: archana_sikarwar@ imu.edu.my)

Harsh Vardhan Batra is with Defense Research Development Establishment, Gwalior, India. also commonly involved in acute pyelonephritis in pregnant women with urinary tract abnormalities such as urolithiases, hydronephrosis or congenital deformities. They may induce sepsis and have a marked tendency to exist as mixed infections or as secondary infections with other pathogenic bacteria [5]. Recently, World Health Organization also warned the community that multidrug resistant bacteria are emerging worldwide which is a big challenge to healthcare. If we didn't take immediate action then antibiotics may lose their power to cure diseases [6]. Multidrug resistant bacteria cause serious nosocomial and community acquired infections that are hard to eradicate by using available antibiotics. Moreover, extensive use of broad-spectrum antibiotics in hospitalized patients has led to both increased carriage of Klebsiella and the development of multidrug-resistant strains that produce extended-spectrum beta-lactamase (ESBL). Antimicrobial chemotherapy depends on the concept that pathogens differ from their hosts in some feature of their biochemistry that renders them susceptible to attack with chemicals that have no, or few, deleterious effects on the host. In effect, chemotherapy requires selective toxicity[7]. Antibiotics are chemically diverse, although there are major families such as the $\beta$-lactams, aminoglycosides, polyketides, and macrolides.

Epidemic strains of cephalosporin resistant K.pneumoniae have been associated with increased morbidity and mortality in hospitalized patients [8]. Since 1983, nosocomial outbreaks of ESBL producing K.pneumoniae infections in Europe [9], the United States and South America have been described [10]. Between 1990 and 1992, 5\% of K.pneumoniae clinical isolates produced ESBLs [11]. In France, 10 to $30 \%$ of K.pneumoniae strains are reported to produce plasmid mediated ESBLs of the TEM or SHV families [12]. Generally, multidrug resistant bacteria are categorized into the Gram positive, Gram negative and acid fast bacilli [13, 14 and 15]. Emergence of Multi-drug resistant bacteria is associated with four resistant strategies used by bacteria that diminish the effects of antibiotics. First one is based on enzymatic modification and inactivation of antibiotics, second is restriction of drug targets access, third is alteration of drug target or even complete diminish of the target and last one is based on phenotypic resistance [16]. We have started our studies with three main objectives. First one is to analyze the severity of multidrug resistance of Klebsiella pneumoniae in India. Second one is to know the challenges faced by healthcare personnel during treatment of multi drug resistant K.pneumonic patients and the last one is to come up with some suggestions to overcome multidrug resistant problem. 


\section{MATERIAL AND METHODS}

We have collected standard and clinical isolates of K.pneumoniae from different places of India and utilized them for their antibiotic resistant ability.

\section{A. Bacterial strains}

Standard culture of K.pneumoniae strain 3296 was collected from Yamaguchi University, Japan whereas total fifty nine clinical isolates were collected from different places of India. Out of all, fifty - four clinical isolates of Klebsiella species were recovered from pus, urine and sputum samples from Armed Force Medical College, Pune, India, four samples from pneumonic patients and one urinary tract infection sample from Patel Chest Hospital, New Delhi, India.

\section{B. Biochemical characterization}

All clinical isolates were examined morphologically for colony characteristics on agar media. Those exhibiting mucoid colonies were processed for biochemical testing. Biochemical test employed were urease production, citrate utilization and fermentation of sugars. Sugar fermentation tests performed were sucrose, glucose, mannitol, lactose, adonitol, dulcitol, melibiose and esculin. Indole test and $\mathrm{H}_{2} \mathrm{~S}$ production on TSI agar, oxidase, catalase and nitrate were also carried out. Besides these tests, motility and growth of organism in potassium cyanide were also checked. For biochemical tests standard procedures were used [17].

\section{C. .Antibiotic sensitivity}

Antibiotic sensitivity of clinical K.pneumoniae isolates was done by Bauer's and Kirby's disc diffusion method [18]. Organisms were grown in BHI broth and inoculated on Mueller Hinton agar plates by sterile swabs and then antibiotic discs were placed on media and pressed gently followed by overnight incubation. The antibiotics that were tested included Ampicillin (20mcg), Cotrimoxazole (25mcg), Piperacillin (100mcg), Gentamycin (10 mcg), Amikacin (30 mcg), Carbenicillin (100mcg), Cefotaxime (30mcg), Ceftizoxime $(30 \mathrm{mcg})$, Tetracycline $(30 \mathrm{mcg})$ and Ofloxacine (5 mcg).

\section{RESULTS}

The standard and clinical isolates of Klebsiella were examined by battery of biochemical tests. Standard K.pneumoniae cultures showed positive reactions for urease production, citrate utilization, catalase reaction and fermentation of sugars like glucose, lactose, sucrose, mannitol,adonitol, melibiose and esculin. Organisms showed negative test for indole production. There was no $\mathrm{H}_{2} \mathrm{~S}$ production on Triple Sugar Iron agar but growth of organism was seen in pottassium cyanide. All fifty-nine clinical isolates exhibiting colonies similar to Klebsiella species were tested biochemically. Thirty-six clinical isolates showed typical common biochemical reaction pattern similar to the one seen with Klebsiella species, being positive to glucose, lactose, sucrose, mannitol and negative to oxidase and indole. When tested by second battery of biochemical reactions that included some rare sugars (adonitol, melibiose, esculin and dulcitol), twenty of them exhibited reactions attributable to majority of K.pneumoniae sub species pneumoniae strain, being positive to adonitol, melibiose, esculin, urease and citrate. They also showed growth in pottassium cyanide. The rest of the isolates had variable reactions with these tests. Results of biochemical tests are shown in table 1.

Antibiotic sensitivity testing of twenty confirmed K.pneumoniae clinical isolates was done on Muller - Hinton agar plates. On the basis of resistance to antibiotic, strains were categorized into three groups i.e. susceptible(S), resistant (R) and moderately susceptible (MS) as shown in table 2. We have used thirteen antibiotics which includes Ampicillin (AS), Co-trimoxazole (BA), Ceflotaxime (CF), Piperacillin (PC), Chloramphenicol $(\mathrm{CH})$, Ciprofloxacin (CP), Ceftizoxime (CL), Tetracyclin (TE), Ofloxazina (OF), Gentamicine (GM), Amikacin (AK), Pefloxan (PF) and Carbenicillin $(\mathrm{CN})$. All of these antibiotics were categorized into three categories on the basis of their sensitivity. Results of one group had strains which were susceptible (over 85\%) to quinolones and aminoglycosides. The second group had strains which were moderately susceptible (intermediate) to antiribosomal antibiotics (chloramphenicol and tetracycline) with $62 \%$ resistant strains. The third group contained strains which were resistant to semi- synthetic penicillins, ampicillin, carbenicillin (76-100\%) and to co-trimoxazole (76\%). Almost five antibiotics oflaxacine, gentamycin, amikacin, pefloxan and ciprofloxacin. showed susceptibility to Klebsiella pneumoniae whereas seven antibiotics carbenicillin, piperacillin, ampicillin, Co-trimoxazole, cefotaxim, chloramphenical and tetracycline showed significant resistance against Klebsiella pneumoniae. Results are shown in fig 1.

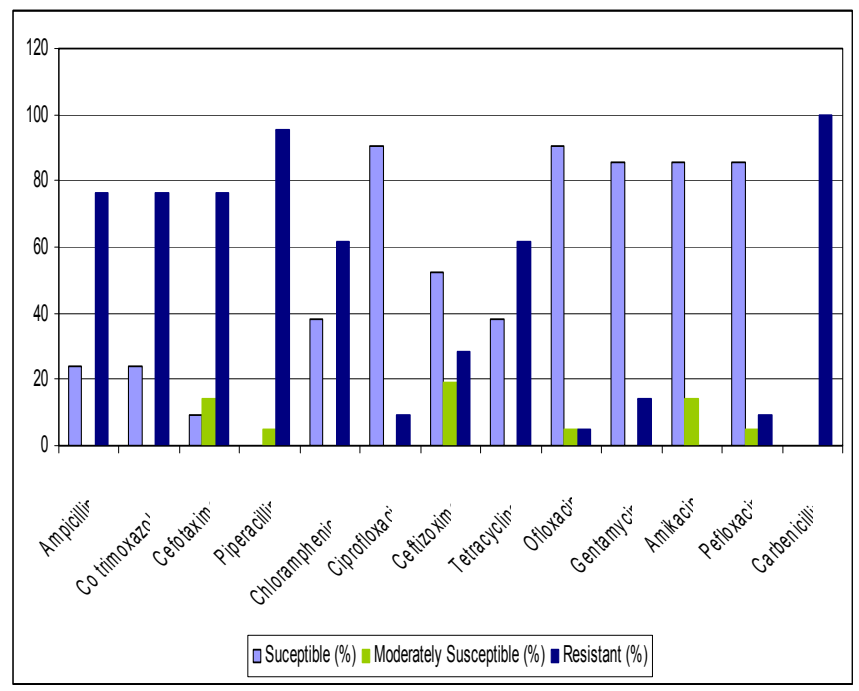

Fig. 1.Antibiotic resistance pattern of Klebsiella pneumoniae isolates

\section{DISCUSSION}

In vitro data showed a wide range of beta-lactams, aminoglycosides, quinolones and other antibiotics which are useful for treatment of Klebsiella infections [19,20 and 21]. Both Gram positive and Gram negative bacteria have cell walls which is composed of heavily cross-linked peptidoglycan layers which are catalysed by cell-wall 
transpeptidases also known as penicillin binding protein(PBP). B-lactam antibiotics disturb peptide bond formation by acting as competitive inhibitors to these PBPs. These result in formation of irreversible covalent bonded penicilloyl-enzyme complexes with weak cross-linked peptidoglycans, thus ease bacteria lyses and death [22]. All confirmed clinical isolates of K.pneumoniae were tested for antimicrobial sensitivity. Fifty four percent of them were found to be multidrug resistant. All the Klebsiella pneumoniae isolates were resistant to carbenicillin and one among them recovered from sputum sample of a pneumonic patient was resistant to all the antimicrobial agents tested except exhibiting a partial susceptibility to amikacin. In such cases the disease is prone to progress to permanent debilitation or death of the patient if, isolation and identification of the causative agent and the subsequent antimicrobial susceptibility testing is not carried out at the early stage of the disease.

In our studies, K.pneumoniae strains from clinical cases were found highly susceptible to quinolones and aminoglycoside, amikacin and gentamycin. At the same time over $60 \%$ strains were found resistant to chloramphenicol and tetracycline. Twenty-eight to $76 \%$ of them were resistant to cephalosporins (ceftizoxime and cefotaxime). Cephalosporins have been widely used as monotherapy and in combination with aminoglycosides for the treatment of Klebsiella infection. Plasmid encoded resistance to broad spectrum cephalosporins is becoming a widespread phenomenon in clinical medicine. These antibiotics are inactivated by an array of different extended spectrum beta lactamases (ESBLs) which have evolved by stepwise mutation of TEM/SHV type beta lactamases. Plasmid encoding these enzymes has been encountered in several members of the family enterobacteriaceae, but are, for unknown reasons, most often harboured by K.pneumoniae. Epidemic and endemic nosocomial infections caused by ESBL producing K.pneumoniae represent a persistent problem in many parts of the world, especially in ICUs $[23,24]$.

The emergence of multidrug resistant strains particularly those involved in nosocomial diseases and the alarming rise in resistance to SHV and ESBL producing groups of antibiotics result in high morbidity and mortality. Early identification of agent, therefore, is important for timely management of patients.Klebsiella has been associated with different types of infections and one of the important aspects of Klebsiella associated infection is the emergence of multi-drug resistant strains particularly those involved in nosocomial diseases. The alarming rise in resistance to SHV and ESBL producing groups of antibiotics result in high morbidity and mortality.TEM- and SHV type ESBL producing Klebsiella pneumoniae were extensively reported worldwide after it was first identified in enterobacterial isolates from India. The high prevalence of these drug resistant strains has further necessitated the requirement of a rapid and accurate identification system for K.pneumoniae. We have found that the isolates were highly susceptible to quinolones and the aminoglycosides. Over sixty percent strains were resistant to chloramphenicol and tetracycline but all the isolates were resistant to carbenicillin.
TABLE 1: BIOCHEMICAL IDENTIFICATION OF CLINICAL SAMPLES (a)

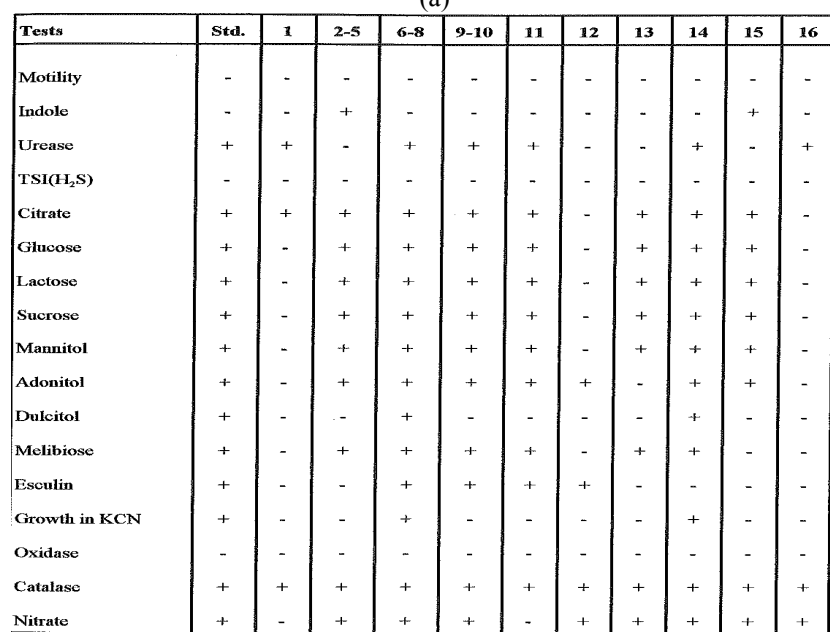

(b)

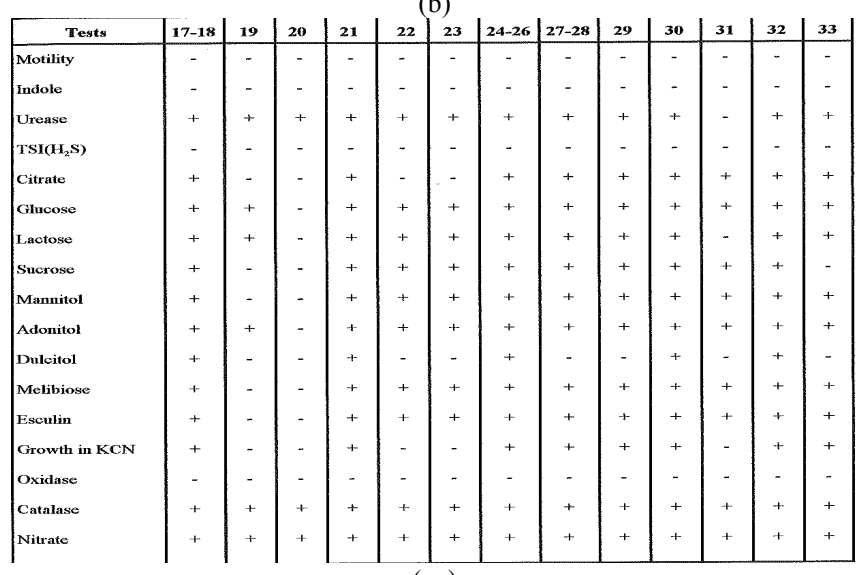

(c)

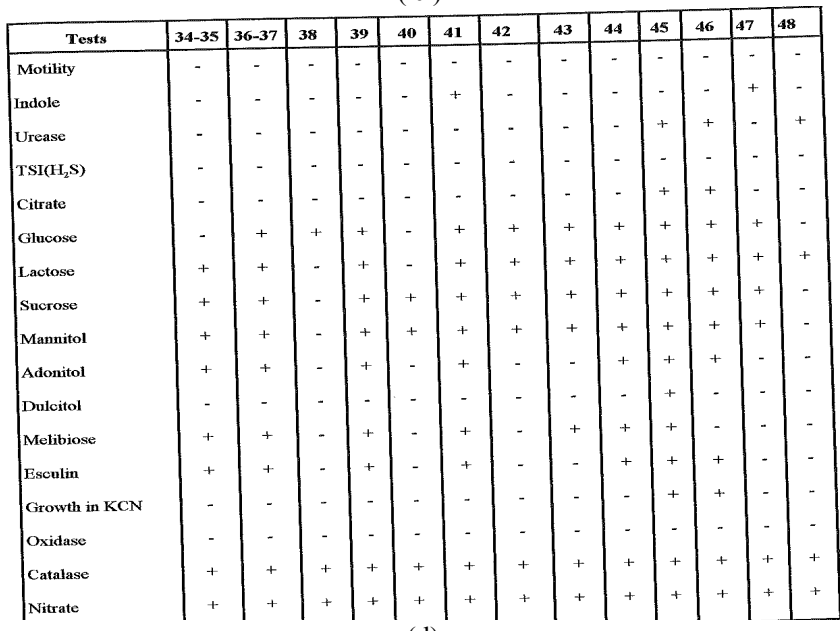

(d)

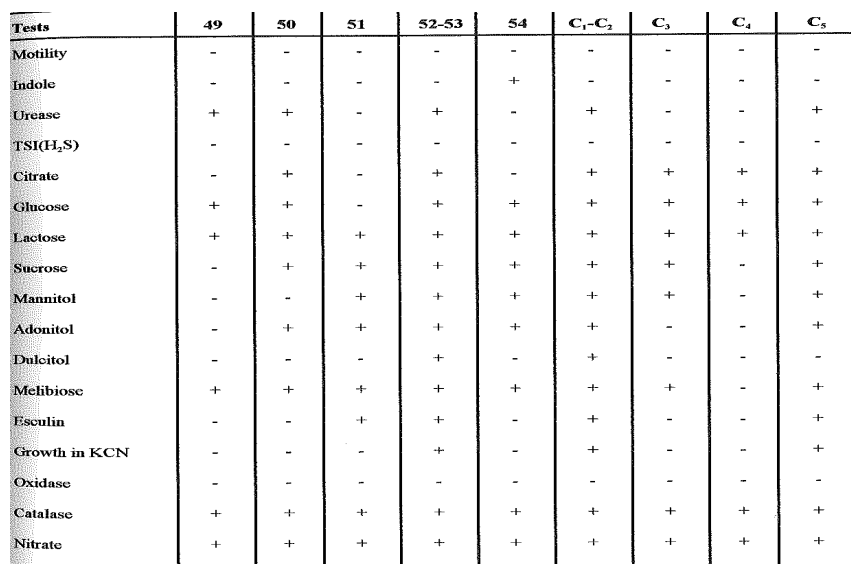


TABLE 2: ANTIBIOTIC SENSITIVITY OF K.PNEUMONIAE ISOLATES Culture AS BA CF PC CH CP CL TE OF GM AK PF CN No.

\begin{tabular}{|c|c|c|c|c|c|c|c|c|c|c|c|c|c|}
\hline & & & S & $\mathrm{R}$ & & S & S & $\mathrm{R}$ & S & S & S & $\mathrm{R}$ & \\
\hline & & P & S & $\mathrm{R}$ & & S & $\mathrm{S}$ & $\mathrm{R}$ & S & $S$ & S & $S$ & \\
\hline & & & $\mathrm{R}$ & $\mathrm{R}$ & & & $\mathrm{R}$ & R & MS & S & $\mathrm{S}$ & MS & \\
\hline & & & S & $\mathrm{R}$ & $s$ & & $S$ & $\mathrm{R}$ & S & $\mathrm{S}$ & $\mathrm{S}$ & $\mathrm{S}$ & \\
\hline & & F & $\mathrm{R}$ & $\mathrm{R}$ & & S & MS & $\mathrm{R}$ & & & $\mathrm{S}$ & & \\
\hline 1 & R & $\mathrm{R}$ & MS & $\mathrm{R}$ & R & $S$ & S & $\mathrm{R}$ & S & $\mathrm{R}$ & S & S & \\
\hline & & & $\mathrm{R}$ & $\mathrm{R}$ & $\mathrm{k}$ & & $\mathrm{R}$ & $S$ & S & $\mathrm{S}$ & MS & $\mathrm{S}$ & \\
\hline & R & $\mathrm{R}$ & S & $\mathrm{R}$ & $\mathrm{R}$ & S & $\mathrm{S}$ & $\mathrm{S}$ & S & $S$ & $\mathrm{~S}$ & S & \\
\hline & K & $\mathrm{R}$ & $\mathrm{R}$ & $\mathrm{R}$ & R & S & $\mathrm{R}$ & S & S & S & $\mathrm{S}$ & S & \\
\hline 7 & $R$ & $\mathrm{R}$ & $\mathrm{S}$ & $\mathrm{R}$ & S & S & $\mathrm{S}$ & $\mathrm{R}$ & S & $\mathrm{S}$ & $\mathrm{S}$ & $\mathrm{S}$ & \\
\hline 8 & $\mathrm{R}$ & $\mathrm{R}$ & $\mathrm{S}$ & $\mathrm{R}$ & S & S & S & $\mathrm{R}$ & S & $\mathrm{S}$ & $\mathrm{S}$ & S & \\
\hline 9 & $\mathrm{~S}$ & S & $S$ & $\mathrm{R}$ & S & S & $\mathrm{S}$ & $S$ & $\mathrm{~S}$ & $S$ & S & $S$ & \\
\hline 30 & $\mathrm{R}$ & $\mathrm{R}$ & $\mathrm{R}$ & $\mathrm{R}$ & $\mathrm{R}$ & S & MS & S & $\mathrm{S}$ & S & MS & $\mathrm{S}$ & \\
\hline 32 & $\mathrm{~S}$ & $\mathrm{R}$ & MS & $\mathrm{R}$ & $\mathrm{R}$ & S & MS & S & S & $\mathrm{S}$ & $\mathrm{S}$ & S & \\
\hline 45 & $\mathrm{~S}$ & $\mathrm{~S}$ & $\mathrm{~S}$ & $\mathrm{R}$ & $\mathrm{K}$ & $\mathrm{S}$ & $\mathrm{R}$ & $S$ & $\mathrm{~S}$ & $\mathrm{~S}$ & S & $S$ & \\
\hline 52 & $\mathrm{R}$ & $\mathrm{R}$ & $\mathrm{R}$ & $\mathrm{R}$ & $\mathrm{R}$ & $\mathrm{R}$ & $\mathrm{R}$ & $\mathrm{R}$ & $\mathrm{R}$ & $\mathrm{R}$ & MS & $\mathrm{R}$ & \\
\hline 53 & P & $\mathrm{R}$ & S & $\mathrm{R}$ & $\mathrm{R}$ & $s$ & $\mathrm{~S}$ & $\mathrm{R}$ & $\mathrm{S}$ & $S$ & $S$ & $S$ & \\
\hline & $s$ & S & MS & $\mathrm{R}$ & S & $\mathrm{R}$ & $\mathrm{R}$ & $\mathrm{S}$ & S & $S$ & S & S & \\
\hline & S & S & S & MS & S & $s$ & S & S & S & S & S & S & \\
\hline & P & $\mathrm{R}$ & S & $\mathrm{R}$ & $\mathrm{R}$ & $\mathrm{S}$ & S & $\mathrm{R}$ & $\mathrm{S}$ & $\mathrm{S}$ & S & $S$ & \\
\hline & R & & S & $\mathrm{R}$ & $\mathrm{R}$ & S & MS & $\mathrm{R}$ & $\mathrm{S}$ & $\mathrm{R}$ & $\mathrm{S}$ & $\mathrm{S}$ & \\
\hline
\end{tabular}

\section{CONCLUSIONS}

Statistical data and evidences from researches prove that multi drug resistant bacteria are emerging worldwide which causes many public health problems and challenges to healthcare. Antimicrobial resistance is a global concern not only because it kills but because it increases health costs and threatens patient care [6]. Moreover, uses of broad spectrum antibiotics, insufficient aseptic condition and technique with inadequate control of infections spread had aggravated this problem. To conclude our research findings data analysis was done using SPSS Package version 18 and the $p$ value of less than 0.1 was considered statistically significant. On the basis of binomial test, we conclude that piperacillin $(\mathrm{P}=0.000)$, carbenicillin $(\mathrm{P}=.000)$, ofloxacine $(\mathrm{P}=.000)$, ampicillin $(\mathrm{P}=.096)$, co-trimoxazole $(\mathrm{P}=0.96)$, and chloramphenicol $(\mathrm{P}=0.035)$ were significantly resistant, whereas cefotaxime and tetracycline were found to be moderately resistant against Klebsiella pneumoniae. To overcome multidrug resistant problem, we would like to suggest that future research plans should focus on the genetic makeup of all multidrug resistant bacteria to understand more about their genes mutations and the effects on antibiotics resistance. Researches on rapid detection of infectious microorganisms should be encouraged. We should also take immediate action to strengthen surveillance and laboratory capacity. Physicians should also promote rational use of medicines to avoid antibiotic drug resistance. All healthcare professionals should work together with pharmacist and laboratory personnel to overcome this problem.

\section{ACKNOWLEDGMENT}

We gratefully acknowledge the Director of the Defense Research and Development Establishment, Gwalior, India, for their support \& encouragement. This work was funded by GATE scholarship. We would like to thank Dr J.Uchiyama (Yamaguchi University, Japan), Armed Force
Medical College, Pune and Patel Chest Hospital, New Delhi for providing us standard and clinical bacterial isolates.

\section{REFERENCES}

[1] P. Nordamann, G. Cuzon and T. Naas “ The real threat of Klebsiella pneumonia carbapenemase-producing bacteria" , Lancet Infec Dis., 2009,9 (4):228-236.

[2] J.R.Graybill, L.W. Marshall, P. Charache, C.K. Wallace and V.K. Melwin "Nosocomial pneumonia: A continuing major problem", ,Am. Rev.Respir. Dis., 1973, 108:1130-1140.

[3] N.B. Mathur, A. Khalib , R. Sarkar and R.K. Puri “ Mortality in neonatal septicaaemia with involvement of mother in management", Ind. J. Pediatri, 1991, 28 (ii) 1259-1264.

[4] S.J. Cryz, R. Furer and R. Germanier "Protection against fatal Klebsiella pneumonia burn wound sepsis by passive transfer of anticapsular polysaccharide", Infect. Immun., 1985, 45: 139-142.

[5] S. Slopek, In "Enterobacteriaceae - Infektionen". (Eds. J. Sedlak and H.Rische), 1968, second ed., 531-557.Georg Thieme,Leipzig.

[6] S.Young Soo, WHO, Western Pacific region, press release , 7 April 2011.

[7] P.C. George , M.W. Salmond, "Antibiotic resistance:adaptive evolution. The Lancet, 2008, Vol 372, S97-S103.

[8] A.D. Dean, A.J. Dean, A.H. Burton and R.C. Dicker " Epi-Infoversion 5: a word processing database and statistics programme for epidemiology on microcomputers" , 1990, VSD. Inc Stone Mountain Ga.

[9] G. Arlet, M. Rouveau, . I. Casin, P.J.M. Bouvet, P.H. Lagrange and

A. Phillippon “ Molecular epidemiology of Klebsiella pneumonia strains that produce SHV-4 B-lactamase and which were isolated in 14 french hospitals", J.Clin.Microbiol. 1994, 32: 2553-2558.

[10] V. Jarlier, M.H. Nicolas, G. Fournier and A. Philippon "Extended broad spectrum B-lactamases conferring transferable resistance to newer beta-lactame, agents in Enterobacteriaceae hospital prevalence and susceptibility patterns", Rev. Infect. Dis. 1988, 10: 867-878.

[11] L. Verbist "Incidence of multiresistance in gram- negative bacterial isolates from intensive care unit in Belgium - a surveillance study" $J$. Infect.Dis., 1991, Supp., 70: 45-53.

[12] G.A. Jacoby and A.A. Medeinos "More extended spectrum B-lactamases" Antimicrob. Agents. Chemother., 1991 ,35:1697-1704.

[13] T. Capriotti, Nursing Pharmacology "Multidrug resistant bacteria create continual need for new antibiotics". MEDSURG Nursing, $2001: 10(3): 147-52$.

[14] C.Salmi3, C. Loncle, N. Vidal 3, Y. Letoumeux3, J.Fantini2, M. Maresca 2, N. Taieb2, J. MariePage's3, J. Brunell ,Squalamine: An appropriate strategy against the emergence of multidrug resistant Gram - Negative bacteria? PLoS one e, 2008, 2765,:3 (7): 1-8.

[15] M Goyal, R.J. Shaw, D.K. Banerjee, R.J. Coker, B.D. Robertson and D.B.Young, "Rapid detection of multidrug-resistant tuberculosis". Eur Respir J., 1997.:10;1120-1124.

[16] S. Henry, M. D. Fraimow, T.Constantine MDb. "Antimicrobial resistance in the Intensive Care Unit: Mechanism, Epidemiology and Management of specific Resistant Pathogens", 2011, Crit Care Clin 27, :27(1):163-205.

[17] R. Cruickshank. "Medical Microbiology, $12^{\text {th }}$ eds. (revised reprient) Edinburg: Churchill Livingstone. 1980, 170-189.

[18] A.W. Bauer, W.M.M. Kirby, J.C. Sherhis and M. Turck, "Antibiotic susceptibility testing by a standardized single disc method", Amer.J.Clin.Path., 1966, 45:493-496.

[19] S.A. Weisenberg, D.J. Morgan , E. R. Witter and D.H. Larone., "Clinical outcomes of patients with Klebsiella pneumonia carbapenemase - producing K.pneumoniae after treatment with imipenem or meropenem.", Diagn.Microbiol Infect Dis., 2009,1 [Medline]

[20] Y.R. Chan, J.S. Liu, D.A. Pociask, M. .Zheng, T.A. Mietzner and. T. Berger, "Lipocalin 2 is required for pulmonary host defense against Klebsiella infection", . J. Immunol., 2009 , 15, 182 (8) 4947-56.

[21] J.M. Adams-haduch,, B.A. Potoski ,H.E. Sidjabat , D.L..Paterson and Y. Doi "Activity to Temocillin against KPC-Producing Klebsiella pneumonia and Escherichia coli", Antimicrob Agents Chemother., 2009,30 [Medline]

[22] M.S. Wilke, L. Andrew, L. Natalie and C .J. Strynadka "B-lactam antibiotic resistant : a current structural prospective" Current Opinion in Microbiology. 2005, 8:525-533.

[23] G. Arlet, M.J. Sanson-le-pors, G. Rouveau, O.M. Fourinier, B. Schlemmer and A. Phillippon, "Outbreak ofnosocomial infections due 
to Klebsiella pneumonia producing SHV-4-B-Lactamases", Eur.J.Clin.Microbiol. Insect.Dis. 1990 ,9:797-803.

[24] K.S. Meyer, C.Vrban, J.A.Eagan, B.T.Berger and J.T. Rahal "Nosocomial outbreak of Klebsiella infection resistant to late-generation cephalosporins" Ann.Intern.Med, 1993, 119:153-358.

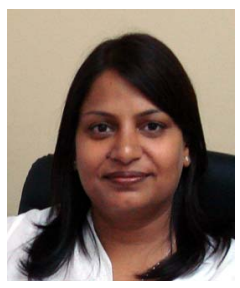

A. S. Sikarwar was born at Gwalior, India on 25 Aug 1971.She have completed her graduation(Biology) in 1991 from Government Science College, Gwalior, INDIA. Dr Sikarwar has done her Master's (Biochemistry) in 1993 from School of Studies in Biochemistry, Jiwaji University, Gwalior, INDIA. She was awarded by her doctor of philosophy in Biochemistry in 1998 from Jiwaji University, Gwalior, India.

She has started her research career as Junior Research Fellow from 1993 for two years which was followed by Senior Research Fellow till 1998. Research grant was given by Ministry of Human Resources, India under the Graduate Aptitude Test for Engineering-93 Scholarship. She has completed her Ph.d. work from Defense Research Development Establishment, Gwalior M.P., India. She was also awarded by Merit Scholarships during her studies She has started her teaching as a lecturer of Biochemistry from Padmashree
Dr. D.Y. Patil Medical Deemed University, Nerul, New Bombay, India in 2001. She joined Rajeev Gandhi College in 2002 as an Assistant Professor of Biotechnology at Bhopal. She also worked as a research volunteer for 627 hours at M D Anderson Cancer Research Center, Houston, Texas, United States in 2006. She was appointed as an Adjunct- Faculty in Biotechnology at Houston Community College, Northeast Campus, Houston, TX, USA in 2007. She joined International Medical University as a Lecturer in 2009 at Kuala Lumpur, Malaysia. She is continuing her services for teaching and research In IMU. During her tenure she has published two research papers entitled "Generation and Characterization of Monoclonal Antibodies Against Klebsiella pneumoniae" Hybridoma, June 2008, Vol. 27, No. 3: 199-203 and "Rapid detection of Klebsiella pneumoniae by capsular polysaccharide antigen" IJCEA, Apr 2011, Vol.2, No.2. She is working on development of rapid detection dot-ELISA kit for Cobra \& Viper snake venom antigen/s.

Dr Archana Singh Sikarwar is a member of "Malaysian society of parasitology and tropical medicine" and "Malaysian society for biochemistry \& Molecular Biology". In 2010, her team was awarded third prize for poster presentation during $7^{\text {th }}$ Annual Scientific Meeting of the Malaysian Society of Hypertension, Kuala Lumpur, Malaysia. Recently she was awarded excellent oral paper presentation in International Conference of Food Engineering and Biotechnology 2011 held at Bangkok, Thailand. 